\title{
AVALIAÇÃO DA PRESENÇA DE METABÓLITOS SECUNDÁRIOS NAS FOLHAS DE XYLOPIA AROMATICA
}

Laís Cardoso Cunha*, Thaiany Ribeiro da Silva, Izabela Natália Faria Gomes, Carolina Corrêa de Menezes, Luciana Alves Rodrigues dos Santos

Lima

Campus Centro Oeste Dona Lindu, Universidade Federal de São João Del-Rei, Divinópolis/MG

*e-mail: thaianys2ribeiro@hotmail.com

\section{Resumo}

A Xylopia aromatica (Lam.) Mart. (Annonaceae) é uma espécie arbórea conhecida como pindaíba, pimenteira e pimenta de macaco. A mesma é encontrada naturalmente no cerrado, nos estados de Minas Gerais, Goiás, Mato Grosso, São Paulo e Mato Grosso do Sul. Quanto ao uso medicinal, esta espécie pode estar associada à atividade antiprotozoária, especificamente sobre Trypanosoma cruzi e Leishmania, devido à presença de metabólitos secundários como alcaloides. Dessa forma, o presente trabalho teve como objetivo avaliar a presença de metabólitos secundários presentes nas folhas de Xylopia aromatica. Aproximadamente $30 \mathrm{~g}$ de folhas de Xylopia aromatica (pimenta de macaco) foram coletadas na cidade de Divinópolis/MG, rasuradas e secadas em estufa a $40{ }^{0} \mathrm{C}$ por sete dias. Posteriormente 2,38g das folhas secas foram maceradas em etanol por sete dias e o extrato foi concentrado no rotavapor. O extrato etanólico foi avaliado para verificar a presença de saponinas, esteroides, terpenos, flavonoides, alcaloides, cumarinas, taninos, antraquinonas e óleos essenciais. As folhas da planta apresentaram um teor de umidade de $47,57 \%$ e o rendimento do extrato etanólico obtido por maceração foi de $14,70 \%$. A análise por cromatografia em camada delgada para detectar a presença de compostos de óleos essenciais revelou três manchas com fatores de retenção de valores 0,32 ; 0,$43 ; 0,94$, respectivamente, os quais são semelhantes aos dos compostos Germacreno-D, $\beta$-ilangeno e $\beta$-cariofileno. As análises fitoquímicas ainda sugeriram a presença de flavonoides e alcaloides, que são descritos como os metabólitos secundários responsáveis pela ação terapêutica desta espécie.

Palavras-chave: Xylopia aromatica, metabólitos secundários, análises fitoquímicas. 